\title{
DETERMINANTS OF MANAGEMENT ACCOUNTING PRACTICES BY MANUFACTURING FIRMS
}

\author{
Joseph Adu-Gyamfi ${ }^{1}$, Prof Kong Yusheng ${ }^{2}$, Abraham Lincoln Ayisi ${ }^{3}$, \\ Wilson Elorm Pekyi ${ }^{4}$ \\ ${ }^{1234}$ School of Economics and Finance, Jiangsu University, Zhenjiang China
}

\author{
Article DOI: https://doi.org/10.36713/epra6814 \\ DOI No: 10.36713/epra6814
}

\begin{abstract}
The impact of the management accounting practices on manufacturing firms in the developing countries cannot be overlook. Management accounting practices adopts and put to practice by these firms has always yielded result, but before management accounting practices are adopted by these firms there are factors that determine their adoption. This paper purposely looks into factors that determine the adoption of management accounting practices by manufacturing firms in Ghana. Various literatures has brought to light that that both internal and external environmental factor such firm size, market rivalry (competition), level of qualification of accounting staff and advanced production technology as the major factors that affect MAPs adoption and want to make analysis with Ghanaian manufacturing firms does these factors affect their choice of MAPS

This study gathered Data from 200 manufacturing firms in Ghana through questionnaires and regression analysis were done using SPSS to determine the impact these factors have on the adoption of MAPs by these manufacturing firms in Ghana. The study identified determinants such as, firm size, market rivalry (competition), level of qualification of accounting staff and advanced production technology has a positive significant impact on the adoption of management accounting practices by manufacturing firms in Ghana. The study recommends that it is important for organizations to identify the best MAPs which can be include in the firms operations to improve performance and longevity of the organization
\end{abstract}

KEYWORDS: Ghana, Management accounting practices, firm size, market rivalry (competition), qualification of accounting staff and advanced production technology

\section{INTRODUCTION}

To be able to yield to maximization of result among most manufacturing firms in the world most of these firms has adhered to some specific management accounting practices in other to accomplish some specific results. The Manufacturing sector is a crucial determinant of industrialization; but in certain part of Africa the sector has always under perform. So to be able to help develop the manufacturing sector a strict practice of effective management accounting practices is needed to help improve efficiency effectiveness and performance (Horngren, Datar, Foster, Rajan, \&.Ittner, 2009). MAPs method assist stakeholders in organization along-with manufacturing companies to scheme, administer and run operating costs and to obtain highest productivity (Gichaaga, 2014)
These actors significantly affect the performance of the organization thus MAPs (Abdel-Al, McClellan, 2013). There are no differences between MAPs and industry and others. Therefore, the pattern of the organization does not impact MAPs but the size of the firm mostly does (Abdel-Al, McClellan, 2013). The impact of MAPs cannot be overlook in today's global market, but before a manufacturing firms choose a specific MAPs to be use or put to practice certain factors are considered before the needed one will be chosen. There seems to be growing concerns about the adoption of MAPs by manufacturers in Ghana, and the adoption rate of MAPs manufacturers remains a serious concern in the more accurate area of management accounting study in economically deprive nations (Ghenhall \&amp; Langfield-Smith, 1998; Saeb 
\&amp; Smith, 2014; Johnson, 2015), although it is recognized as a major contributor to business performance. Association of Ghana Industries AGI (2013) attributed the poor performance of most manufacturing firms in Ghana to competition, hightech advances, electricity and gas and cost of running manufacturing companies and many others. And as a result many also refusing to put into practice the best MAPs. This paper aim is to examine the important element affecting the reason behind the use of certain MAPs in Ghana's industrious firms

\section{RESEARCH PROBLEM}

Businesses today are becoming different, ambitious and assertive due to the competiveness that surround most business in the world, and a such most firm are identifying more blueprint that will guarantee economic affluence. Rivalry may be ascribing to trade coinage, high-tech advancement and the wavering request of buyers. Rivalry amidst profit making firms can enforce the stakeholders (management) to create business methods and schemes that would influence business to achieve a better profit mechanism. Environmental factors has mostly affected manufacturing companies and some are entrepreneurial ignorance, impecunious trade techniques, technology, market rivalry, creativity and risk elements Amoako (2013), And hence adopting the best management accounting methods The few literature in Ghana that concentrate on management accounting practices are Abor and Effah (2011); Amoako (2013); Mbawuni and Anertey (2014) which concentrate on small scale enterprises and telecommunication sector respectively? These literatures focus on the impact of MAPs of practices on SME and Telecommunication industry and how it affect the business performance of industrious companies in Ghana, The periodical unwillingness to use MAPs by industrial firms as seen view by Nandan (2010); Lopez \& Hiebl (2015) as a stimulus to the slow sedate of industrial firms, Thus there is requirement for progressively integrative research to determine the contentions of the determinants that impact the adoptions of MAPs by theses manufacturing firms, thus why most firms are not using MAPs and what are the factors affecting their adoption by these manufacturing firms in Ghana

\section{OBJECTIVE OF THE STUDY}

$>$ To examine the elements that impacts management accounting practices by industrial firms in

\section{RESEARCH QUESTIONS}

These questions were asked base on the objectives;

$>$ What factors affect the adoption of MAPs of industrial (manufacturing) companies in the Ghana?

\section{HYPOTHESES}

H01: Firm's size has a significant positive influence on MAPs adoption by manufacturing firm in Ghana

H02: market rivalry (competition) has a significant positive influence on MAPs adoption by manufacturing firm in Ghana

H03: level of qualification of accounting staff has a significant positive influence on MAPs adoption by manufacturing firm in Ghana

H04: High-Tech advancement in production has a significant positive influence on MAPs adoption by manufacturing firm in Ghana

\section{LITERATURE REVIEW}

A contingency theory states that the is no best ways to manage or organize a firm to help a firm make inform decisions but rather these decision is based on the situations that is happening at a particular time in a company both internal and external. (Morton \& $\mathrm{Hu}$, 2008) explain that contingency theory is the best link between MAPs to be use in organization in times of contingency to help in effectiveness and efficiency,in contingency approach management admit that better way of running a firm is dependent on the context of the situation at hand either using a single or fixed approach which will not be effective in the organization running. Otley (1980) also explain that there is no definite MAPs that can handle or solve all organizational problems so such a such strategies are adapted on how and best MAPs fit in terms of contingencies

Laying out consideration transition in trade settings has most of the time affected what MAPS will be chosen at that particular time Waweru, Hoque and Uliana (2005) was also of the view the business setting of most firms has change as a result of high-tech advancement and favorable rivalry setting and economic decline. The quick adjustment in trade settings most of the time is as a result of world changes rivalry among business and the economic factor of the country the business is within swift changes of firm settings recently into global, competitive and these factors impact fully affect the type of MAPS to choose both industrious firms and non-industrious firms, whether small or large or moderate and either it is establish as a profit venture or not (Yazdifar \&Tsamenyi, 2005). 
It turns out those potential emergency elements that describe the efficacy of MAPs are mostly determines by environment, technology, size, strategy

This study examines four determinants of MAPs: the size of the Firm, the market rivalry (competition) Accounting Employees understanding level and High- tech production advancement

\section{Firm Size}

The size of a firm has always being a major determinant to the choice of MAPs by manufacturing firms. A study by Mbawuni and Anerley (2014) was of the view that MAPs adopted in Ghana depends on the nature and organizational size and his study was on telecommunication in Ghana, also Abder-Kader \& Luther (2008) was of the same view that the size of the firm impact the specific MAPs to be chosen, this being that big firms find it easy to choose modernized and complicated MAPs as compare to SMEs and other smaller firms Organization size can basically be determined by number of staff in the firm also the paid up capital can be used to determines the size of the firm as asserted by (Tuanmat, \& Smith, 2011). Ismail and Mahmoud (2012) study also done in Egypt stated that the size of organization determines the MAPs adopted by manufacturing firms in Egypt, their study stated clearly that modern and sophisticated MAPs are used big firms whiles traditional and simple MAPs are used by firms of a smaller size because of their convenience

\section{Market Competition}

Another determinant of MAPs is market (rivalry) competition influence on manufacturing firms. Market rivalry (competition) can be separated into two terms market and competition; market can be describe as two or more entities comes together to exchange goods or services or any other information. And when similar product are sold at the market by different firms or organization the competition emerges

All organization aim is to be the preferred destination to consumers when it comes to choosing a specific product or services and because of that they in terms improve their product quality delivery and cost and other flexible component to give them competitive advantage over their competitors (Hussain et al., 2015) firms are mostly push to the corner in making choices of MAPs that will be able to help them to deal with competition they might be facing in the market. Andersén \& Samuelsson (2016) was of the view that a firm's increased efficiency is induced by numerous variegated components that serves as a higher worth, different, and by wisely appropriating restrained resources. Ocloo et al. (2018) was of the view that market rivalry is a determinant of MAPs very necessary in gaining a competitive advantage

\section{Level of Qualification of Accounting Staff and owners}

When it comes in the putting these MAPS into practice for effective and efficient maximization of profit and productivity the accountant is always needed and hence his level of qualification comes to play. Mostly the MAPs adopted will depends how these accountant understand them and how they will be put them into practice. Study done by Carey (2015) discovered that in most part of Europe and America people with professional degree and maters of accounting are trusted most by these companies and hence their services is always needed so mostly the level of accountant available will determines the MAPs that will be adopted because he or she will put into practices what he or she understand Ahmad (2012) study stated clearly that there is a link between accounting staff qualification and MAPs adopted in Malaysian SMEs again the research discovered that the educational level of accounting staff positively affect the application of accounting information. Also, most business decisions made by accounting staff and owners of firms has an impact on the performance of the organization so adequate knowledge understanding and skills is needed to perform these steps.

\section{Advanced Production Technology}

Most modern day manufacturing firms are all adopting to high-Tech advancement in term of their production as it result in a faster efficient and effective way in terms of their production

Technological advancement can be seen as key components in achieving a rivalry advantage over other businesses because it allows companies to be become more efficient by improving production and helping it to be done in a more faster rate (Ahmed and Muhammad Shari, 2015; Ahmed and Mohammed Sabari, 2015; Ahmed and Mohammed Sabri, 2015; Ahmed Mohammad Sabari, 2015). Jamil et al. Leite et al.'s (2015) Studying the relationship between Advanced manufacturing technology and MAPs, found that technology in the textile industry is developing rapidly in recent decades, This technology is reflected at some stage in the manufacturing process which is electronics and automated with such high technology available in most manufacturing firms it influence the MAPs that mostly are supposed to be used by these firms. A higher level of technology imposed by manufacturing firms requires sophisticated management plans that will lead to higher turnover (Marty and Quuss, 2018). This will require support 
from management, company size, resources and choice of MAPs that will be used by these firm infrastructure (Schneider et al., 2015). Leading to the

\section{Theoretical Framework}

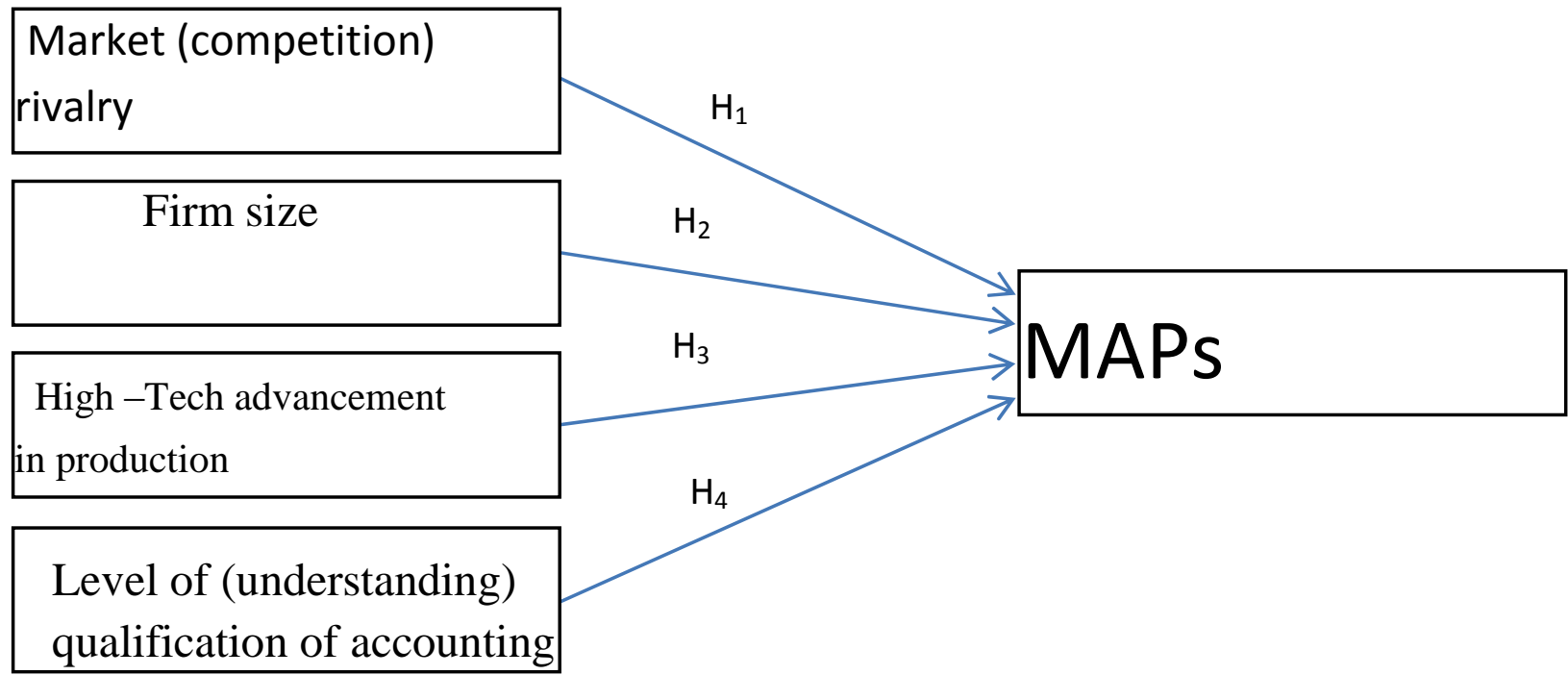

\section{METHODOLOGY}

The method use for this research was cross sectional survey, 200 manufacturing firms were targeted as the target population from industrious companies registered under (AGI) Association of Ghana industries, Census was use rather than sampling in this study Therefore, data were obtained from all 200 firms. Out of which 30 refuse to respond to the questionnaires sent to them this representing $85 \%$.response rate The data needed for the study were collected via a self-administered questionnaire were used in gathering the data needed for the study, accuracy, validity and reliability of the questionnaire were tested with a pilot testing. Information gathered from the literature review was used to design the questionnaire. In achieving our specific objective data was collected base on that and the respondents' background. This study uses multiple regression analysis methods in testing the relationship that exist between these determinants of MAPs and how it affect their adoption by these manufacturing firms
And thus the regression model of the second hypotheses:

MAPs $=\alpha+\beta_{1}(\mathrm{MC})+\beta_{2}(\mathrm{FS})+\beta_{3}(\mathrm{LAS})+\beta_{4}(\mathrm{TAP})$

$+\mathrm{s}$

This equation can be expatiated as

Variable (Dependent) is MAPs

Variables (independent) are;

Market rivalry (competition) (MC)

Firm size (FS)

Level of qualification of accounting staff (LAS)

Technological advancement in production (TAP)

The coefficients of the independent variables serving as agents or factors determining the adoption of MAPs is expected to have a positive significant effect 
Demography

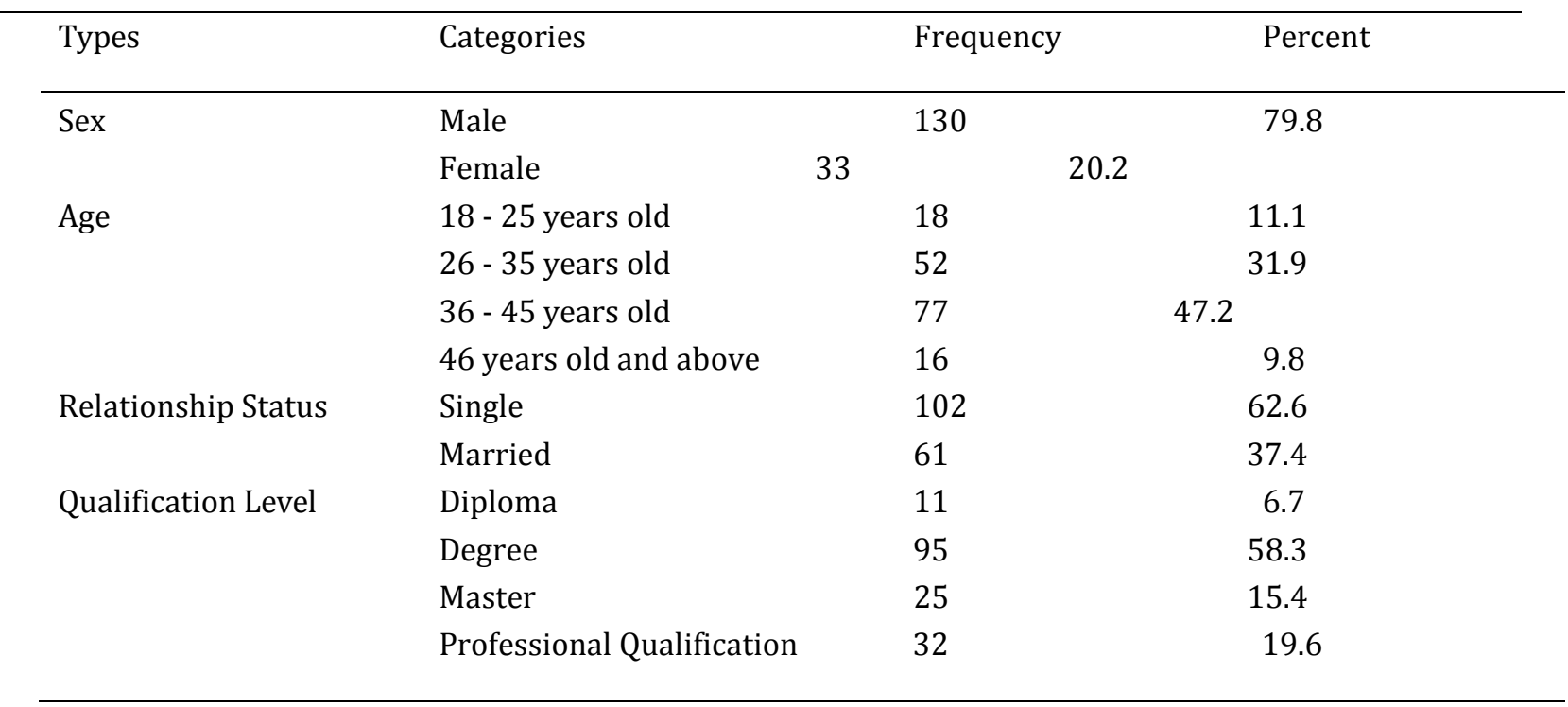

Background Data of Some selected Manufacturing companies in Ghana

\begin{tabular}{lll}
\hline Variable & Frequency & Percentage (\%) \\
\hline Business analysis & 14 & 8.6 \\
Building materials & 63 & 38.6 \\
Food, water and beverage & 20 & 12.3 \\
Plastics & 17 & 10.4 \\
Metal and allied & 12 & 7.4 \\
Pharmaceutical & 13 & 7.9 \\
Leather & 15 & 9.3 \\
Textiles & 9 & 5.5 \\
Engineering and electronics & $\mathbf{1 6 3}$ & $\mathbf{1 0 0}$ \\
Total & &
\end{tabular}




\section{Regression Analysis}

\section{Dependent Variables}

\begin{tabular}{llllll}
\hline Variable & Beta $(\boldsymbol{\beta})$ & t-stats & Std. Error & P - value & $\mathbf{R}^{2}$ \\
\hline Constant & 1.042 & 2.095 & 0.497 & $0.004^{* * *}$ & 0.683 \\
FS & 0.102 & 3.110 & 0.029 & $0.000^{* * *}$ & \\
LAS & 0.071 & 1.656 & 0.037 & $0.032^{* *}$ & \\
MC & 0.088 & 1.886 & 0.021 & $0.0227^{* *}$ & \\
TAP & 0.065 & 2.935 & 0.024 & $0.002^{* * *}$ & \\
\hline
\end{tabular}

Diagnosis

\begin{tabular}{lc} 
Adj. R2 & 0.659 \\
F-stat & $\begin{array}{l}103.221 \\
(0.000)\end{array}$ \\
Sums of Square & of125.683 \\
regression & 186.750 \\
Total sums of square & 163 \\
\hline
\end{tabular}

Sign. Level: $(* * *$ at $1 \%, * *$ at $5 \%)$

\section{DISCUSSION OF FINDINGS}

From the table above we see the regression model that will help as to analyses the determinants influencing the choice of MAPs, by these manufacturing firms, the fitness of the model can be determine by statistics of the $\mathrm{R}^{2}$ and the adjusted $\mathrm{R}^{2}$. from the table the result of $\mathrm{R}$ Square is 0.683 . This shows that, the chosen independent variables are indeed determinants influencing the choice of MAPs by these firms, this indicate that the adoption of maps by these firms are influence by these determinants by $68.3 \%$ This shows that the whole model is strongly significant

From the table, firm size (FS) has the highest coefficient and t-statistics in terms of level of adoption by manufacturing firms in Ghana. Firm size a factors of choosing MAPs by these manufacturing firms has the highest t-statistic of 3.110 compare to other determinants. With a coefficient of 0.102 (P-value $=$ 0.000).

Also level of qualification can be seen from the table that it influence the adoption of MAPs as it has a coefficient of 0.071 with a $(\mathrm{P}$-value $=0.032)$ this also indicate that the level of qualification of staff is positively influence the adoption of MAPs by manufacturing firms
Lasting from the table it can also be seen that market competition and advance in technology in production also positively affect the adoption of MAPs as it shows the following $\mathrm{p}$ - value and co efficient respectively $\mathrm{P}$-value are 0.0227 and 0.002 and with a coefficient 0.088 and 0.065

\section{CONCLUSION AND RECOMMENDATIONS}

The main aim of the study was to determine the factors that influence the adoption of MAPs by manufacturing firms in Ghana. Four factors were seen to be the determinants influencing the adoption of MAPs by theses manufacturing firms in Ghana and they were market competition, advancement in technology in production, level of qualification by accounting staff and the size of the firms.

From the finding we were able to determine that all these factors positively influence the choice of maps by these manufacturing firms in Ghana.

The size of the organization or the firm was seen to be the major determinant of MAPs in Ghana as also proves by these studies by (Ahmad, 2012; Mbawuni \& Anertey, 2014; Ismail \& Mahmoud, 2012). Where they state clearly that firm size has significant influence in the adoption of MAPs 
This study after will be addition to assumptions of management accounting in progressing economies by fixating on the practices of industrial firms in Ghana. This study will contribute results that will aid decision makers in future decision making. And also result from this study will be instructional to policy makers' with the intention of progressing on their management accounting skills of staffs as it influence the MAPs being chosen which will affect the performance and productivity of organizations. The result will also contribute to existing literature

\section{REFERENCES}

1. Abdel Al, S. F., \& McLellan, J. D. (2013). Strategy and management accounting practices alignment and its effect on organizational performance. Journal of Accounting - Business \& Management, 20(1)1, 1-27.

2. Abdel-Kader, M. and Luther, R. (2008). The impact of firm characteristics on management accounting practices: A UK-based empirical analysis. British Accounting Review, 40 (1). pp. 2-27. ISSN 08908389. http://dx.doi.org/10.1016/j.bar.2007.11.003

3. Ahmad, $K$ (2012). Factors explaining the extent of use of management accounting practices in Malaysian medium firms. Asean Entrepreneurship Conference 2012.

4. Ahmad, K. (2014). The adoption of management accounting practices in Malaysian small and medium-sized enterprise. Asian Social Science, 10(2), 236-249.

5. Albu, N., \& Albu, C. (2012). Factors associated with the adoption and use of management accounting techniques in developing countries: The case of Romania. Journal of International Financial Management \& Accounting 23(3), 245 276.

6. Basso ,D. Pesarin, F., Salmaso, S., \& Solari, A. (2009). Permutation Tests for Stochastic Ordering and ANOVA: Theory and Applications with R. US: New York.

7. Brown, A., Booth, P., \& Giacobbe, F. (2004). Technological and organizational influences on the adoption of activity-based costing in Australia. Accounting and Finance, 44(3), 329-356.

8. Cadez, S., \& Guilding, C. (2008). An exploratory investigation of an integrated contingency model of strategic management accounting. Accounting, Organization and Society, 33, 836-863.

9. Collis, J., \& Jarvis, R. (2002). Financial information and the management of small private companies. Journal of ijbm.ccsenet.org International Journal of Business and Management Vol. 12, No. 10; 2017184

10. Small Business and Enterprise Development, 9(2), 100-110.
11. Cooper, C. R., \& Schindler, P. S. (2008). Business Research Methods (10th ed.). Boston: McGrawHill.

12. Drury, C. (2004) Management and Cost Accounting (6th ed.). London: Thomson Learning.

13. Garrison, R., Noreen, E.W., \& Seal, W. (2006). Management Accounting. McGraw-Hill.

14. Haldma, T., \& Laats, K. (2002). Influencing contingencies on management accounting practices in Estonian manufacturing companies. University of Tartu - Economics and Business Administration Working Paper No. 13

15. Hair, B. B., \& Anderson. (2010). Multivariate Data Analysis (7th ed.). US: Pearson Prentice Hall.

16. Ismail, N. A., \& King, M. (2007). Factors influencing the alignment of accounting information systems in small and medium sized Malaysian manufacturing firms. Journal of Information Systems and Small Business, 1(2), 120 .

17. Ismail, T. H., \& Mahmoud, N. M. (2012). The influence of organizational and environmental factors on cost systems design in Egypt. British Journal of Economics, Finance and Management Science, 4(2), 31-51.

18. Leite, A. A, Fernandes, P. O., \& Leite, J. M. (2015). Contingent factors that influence the use of management

19. Accounting practices in the Portuguese textile and clothing sector. The International Journal of Management Science and Information Technology. Special Issue: Spanish-Portuguese Scientific Management Conference, (59-77).

20. Mbawuni, J., \& Anertey, A. (2014). Exploring management accounting practices in emerging telecommunication market in Ghana. Accounting and Finance Research, 3(4), 71-85.

21. McLellan, J. D. (2014). Management accounting theory and practice: Measuring the gap in United States Business. Journal of Accounting - Business \& Management, 21(1), 53-68.

22. Otley. D. T. (1980). The contingency theory of management accounting: Achievement and Prognosis. Accounting, Organizations and Society, 5(4), 413-428.

23. Rosmawati, M., \& Normah. (2004). The current state of management accounting practice in selected Malaysian companies: An empirical evidence. International Business Management Conference.

24. Sekaran. (2006). Research Methods for Business: A skill building approach (4th ed.). US: Wiley.

25. Sunarni, C. W. (2013). Management Accounting Practices and the Role of Management Accountant: Evidence from Manufacturing Companies throughout Yogyakarta, Indonesia. Review Journal of Management, 18(2), 233- 248

26. Tuanmat, T. Z., \& Smith, M. (2011). Changes in management accounting practices in Malaysia. Asian Review of Accounting, 19(3), 221-242. 